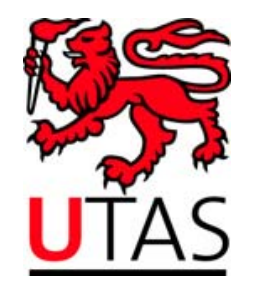

SCHOOL OF ECONOMICS AND FINANCE

Discussion Paper 2011-05

\title{
A SVECM Model of the UK Economy and
} The Term Premium

\author{
Mardi Dungey \\ and \\ M. Tugrul Vehbi
}

ISSN 1443-8593

ISBN 978-1-86295-633-9 


\title{
A SVECM Model of the UK Economy and The Term Premium*
}

\author{
MARDI DUNGEY ${ }^{+}$and M.TUGRUL VEHBI ${ }^{+*}$ \\ ${ }^{+*}$ CFAP, University of Cambridge and CAMA, ANU \\ Cambridge. CB1 2AG. UK \\ (e-mail: mtv20@cam.ac.uk) \\ + University of Tasmania and CAMA, ANU \\ Hobart, Tasmania. 7001. Australia \\ (e-mail: mardi.dungey@utas.edu.au)
}

\begin{abstract}
The term premium is estimated from an empirically coherent open economy VAR model of the UK economy where the model specifically accounts for the mixed nature of the data and cointegration between some variables. Using this framework the estimated negative term premia for 1980-2007 is decomposed into its contributing shocks, where the role of inflation and monetary policy shocks are shown to be dominant in the evolution of the term premium. Projecting into the 2008 crisis period reveals the extent of the shocks to the UK economy, and also shows the similarities in term premia behaviour with those experienced during the 1998 Russian crisis.
\end{abstract}

Keywords: Structural VECM models, term premium, crisis

JEL Classification: E43, E52, C51, C32

${ }^{*}$ We thank Renée Fry and Denise Osborn for helpful comments. Dungey acknowledges financial support from ARC Discovery Project \#DP0664024 


\section{A SVECM Model of the UK Economy and The Term Premium}

The unusual lack of sensitivity of long-term interest rates in major international bond markets to the large rise in US short rates during June 2004-June 2006 was famously described by the incumbent Chairman of the Federal Reserve as a conundrum (Greenspan, 2005). Explanations for this phenomenon include the existence of the global savings glut, flight to quality, loose monetary policy or falls in risk premia. No consensus has yet emerged on which was the most important. This paper focusses on the latter explanation and addresses the important question of quantifying the extent to which macroeconomic shocks contribute to changes in term premia over time in a model consistent fashion. Although, in theory, the term premium is simply the difference between a current long-term rate and the sum of expected short-term rates prevailing over the same period, there is no single way of constructing expectations for the short-term rates. Methods offered in the literature to derive term premia include surveys, empirical-based models such as VAR, structural approaches using DSGE models or the use of no-arbitrage term structure models. Term premia estimates vary significantly across these different methods (see Rudebusch et al., 2007, for an overview).

We build a small open economy VECM model of the UK economy, from which estimates of time-varying term premia are constructed using an approach adapted from Carriero et al. (2006). The path of the term premium can be decomposed into the shocks to macroeconomic conditions contributing to its evolution over the sample period. The results show the particular prominence of inflation and monetary policy shocks in determining movements in the UK term premium over the past 20 years. By projecting the model into the global financial crisis of 2007-2008 we provide an assessment of the extent of shocks affecting the UK economy during the crisis and the consequences for the associated projection of the term premia during the crisis.

There are only a few studies that have estimated the term premia using UK data. Joyce et al. (2008) apply a standard no-arbitrage term structure model to UK real term structure and find that time-varying term premia is an extremely important determinant of movements in long real forward rates. In a related study, Joyce et al. (2010) develop an essentially affine model of the UK real and nominal term structures and find that the conundrum of unusually low long-term real rates can mainly be attributed to a fall in real term premia. Bianchi et al. (2009) use a closed economy time varying coefficients VAR model with observable and latent factors to estimate the term premia.

Unlike Joyce et al. (2008,2010) and Bianchi et al. (2009), the current paper specifically recognizes the open economy structure of the UK economy, and emphasizes the importance 
of appropriate VAR specification in obtaining credible term premia estimates. Specifically, in this model, exclusion restrictions and cointegration are combined to identify the model, while maintaining empirical coherence in the spirit of Akram and Nymoen (2009) who show the policy importance of models providing good representations of the underlying data. The combination of identification methods harnesses the empirical properties of the data, employing a mix of $\mathrm{I}(1)$ and $\mathrm{I}(0)$ variables and identifying and recovering the effects of permanent and temporary shocks. The choice of the methodology applied in the paper reflects our motivation to provide a better understanding of the economics behind the determinants of term premia, rather than trying to find the best statistical fit to UK yields. To our knowledge, our paper provides the only open economy modeling framework that analyses the evolution of a model consistent term premia for the UK since her adoption of the inflation targeting regime in 1992.

As such, this paper contributes to a continuing literature on modelling the UK as a benchmark small open economy, for example Dennis et al. (2007), Leitemo (2006), Ravn (1992) and Beenstock and Longbottom (1981), and to the emerging literature on combining methods of identification in VAR models in Dungey and Fry (2009).

The modelling output reveals a distinct decrease in the magnitude and volatility of shocks to the UK economy post 1992, around the time of the introduction of inflation targeting. This is consistent with the literature on the Great Moderation (Blanchard and Simon, 2001) and the attribution of this to inflation targeting in Cecchetti et al. (2006). While foreign demand shocks have had considerable impact on domestic output fluctuations, the contributions of monetary policy shocks to business cycle fluctuations are relatively small. Out-of-sample model projections for 2007 show that it performs reasonably well for output and interest rates. Projection into the crisis period reveals the extreme nature of the shocks hitting the UK economy in 2008.

The term premia estimates for the period leading up to the financial crisis reveal a timevarying term premium which has tended to be negative over most of the period since 1995, albeit punctuated by positive observations which can be casually associated with events such as UK election dates. The decomposition from the model indicates the predominant influence of inflation and monetary policy shocks on the evolution of the term premia over the sample, particularly evident since the move to inflation targeting. This is consistent with the fact that the nominal term structure may reflect inflation risk premia as well as real term premia. In the crisis period model projections, shocks to monetary policy are particularly influential in understanding the extent to which the term premium declined.

The paper proceeds as follows. Section 2 describes the model identification and the methodology to estimate the term premium in a model-consistent fashion. Section 3 presents 
the precise empirical specification of the UK model and Section 4 describes the empirical results, including the projection of the model into the crisis period. In Section 5, we use the model to estimate the 10-year time-varying term premia and assess the contributing shocks. Section 6 concludes.

\section{Methodology}

The methodology draws upon the literature using VAR models to derive model-consistent, risk-neutral expectations of long-term interest rates (Carriero et al., 2006) where at each date the VAR can be used to forecast the short rate over a given horizon where the risk-neutral, long-term rate and the term premium are calculated. We extend the simple closed economy VAR structures used in these studies and model the UK as a small open economy where the US is treated as the foreign economy. The dynamics of the model is further enhanced by introducing an error-correction term derived from the cointegration relationship among the outputs of two countries and the real exchange rate. Using the methodologies pioneered in Pagan and Pesaran (2008), the model employs a mix of $\mathrm{I}(1)$ and $\mathrm{I}(0)$ variables as well as identifies and recovers the effects of permanent and temporary shocks, thus providing a better representation of the underlying data for proxying the model-consistent expectations of short-run rates. Our methodology allows us to decompose the contribution of different shocks to the forecast-error variance of the term premia. A detailed description of the methodology follows.

\subsection{VAR Identification}

Suppose that the economy is described by a $\operatorname{VAR}(\mathrm{p})$ model of the form

$$
A(L) \mathbf{y}_{t-l}=\mathbf{u}_{t}
$$

where $\mathbf{y}_{t}$ is a $(n \times 1)$ vector of observable variables, $A(L)$ are $(n \times n)$ parameter matrices, $L=\left(I-L^{1}-L^{2} \ldots L^{p}\right)$, and $\mathbf{u}_{t}$ is an $(n \times 1)$ vector of unobservable error terms with $u_{t} \sim\left(0, \Sigma_{u}\right)$.

Assuming that all the variables are at most difference stationary, the generic model can be written as a VECM in the form

$$
B_{0} \Delta \mathbf{y}_{t}=\Pi^{*} \mathbf{y}_{t-1}+B(L) \Delta \mathbf{y}_{t-l}+\varepsilon_{t}
$$

where $B_{0}$ is a matrix of contemporaneous interactions, the $B(L)$ are $(n \times n)$ matrices of short-run dynamics parameters, $L=\left(L^{1}+L^{2} \ldots L^{p}\right)$, $\Pi^{*}$ is the structural matrix and $\varepsilon_{t}$ is a 
$(n \times 1)$ structural form error with zero mean and covariance matrix $I_{K}$.

Assuming that the $B_{0}$ is invertible, equation (2) can be written as

$$
\Delta y_{t}=\Pi y_{t-1}+\Gamma(L) \Delta y_{t-1}+u_{t}
$$

where $\Pi_{t}=B_{0}^{-1} \Pi^{*}, \Gamma(L)=B_{0}^{-1} \Gamma(L)$ and $\mathbf{u}_{t}=B_{0}^{-1} \varepsilon_{t}$. When $\Pi$ has a reduced rank such that $\operatorname{rank}(\pi)=r<n$ then $\Pi=\alpha \beta^{\prime}$ where $\beta$ is a $(n \times r)$ matrix of long-run relationships, $\alpha$.is a $(n \times r)$ matrix of the "speed of adjustment" coefficients and $\mathbf{u}_{t}$ is a white noise error with zero mean and covariance matrix $\Sigma_{u}$.

In this paper, identification is achieved by combining exclusion restrictions on $B_{0}$ and $\Gamma(L)$ with the insights of Pagan and Pesaran (2008) whereby the existence of cointegration among the $I(1)$ variables of the system provides extra identifying restrictions. ${ }^{1}$

Equation (3) has the following Beveridge-Nelson Moving Average (MA) representation (see Lutkepohl and Kratzig, 2004 for details):.

$$
\mathbf{y}_{t}=F \sum_{i=1}^{t} \mathbf{u}_{i}+\sum_{j=0}^{\infty} F_{j}^{*} \mathbf{u}_{t-j}+\mathbf{y}_{0}
$$

where the matrix $F=\beta_{\perp}\left(\alpha_{\perp}^{\prime}\left(I_{n}-\sum_{i=1}^{p-1} \Gamma_{i}\right) \beta_{\perp}\right)^{-1} \alpha_{\perp}^{\prime}$ and $\mathbf{y}_{0}$ contains the initial values. With $r$ cointegrating vectors, the rank of $F$ is $n-r$ and there are $n-r$ independent common trends. The long-run effects of shocks are represented by the first term in equation (4), $F \sum_{i=1}^{t} \mathbf{u}_{i}$ , which captures the common stochastic trends. The second term in the expression is an infinite-order polynomial with coefficients $F_{j}^{*}$ going to zero as $j \rightarrow \infty$, thus, representing transitory shocks to the system. The common driving stochastic trends are the variables $\alpha_{\perp}^{\prime} \sum_{i=1}^{t} \mathbf{u}_{i}$, where their factor loadings are given by $\beta_{\perp}\left(\alpha_{\perp}^{\prime}\left(I_{n}-\sum_{i=1}^{p-1} \Gamma_{i}\right) \beta_{\perp}\right)^{-1}$. Replacing $\mathbf{u}_{t}$ s by their structural counterparts, we obtain

$$
y_{t}=F \sum_{i=1}^{t} B_{0}^{-1} \varepsilon_{t}+\sum_{j=0}^{\infty} F_{j}^{*} B_{0}^{-1} \varepsilon_{t-j}+\mathbf{y}_{0}
$$

where the effects of short and long-run structural shocks can be obtained. The long-run effects can be captured by $F B_{0}^{-1}$, which has a rank $n-r$ since $r k(F)=n-r$ and $B_{0}$ is not singular. Therefore, while $r$ of the structural shocks have transitory effects, $n-r$ of them will have a permanent effect and can be restricted to zero, providing $r(n-r)$ independent identifying restrictions.

Using a Wold decomposition and assuming that the first $(n-r)$ shocks are permanent

\footnotetext{
${ }^{1}$ The combination of identification restrictions in VAR models is explored in Dungey and Fry (2009).
} 
$\left(\varepsilon_{1 t}\right)$, we can write $\Delta \mathbf{y}_{t}$ as

$$
\Delta \mathbf{y}_{t}=C(L) B_{0}^{-1}\left(\begin{array}{l}
\varepsilon_{1 t} \\
\varepsilon_{2 t}
\end{array}\right) .
$$

where $C(L)$ is a polynomial of order $q$ in the lag operator.

For the remaining shocks $\varepsilon_{2 t}$ to be transitory requires

$$
F B_{0}^{-1}\left(\begin{array}{c}
0_{(n-r) * r} \\
I_{r+k}
\end{array}\right)=F \alpha=0
$$

which implies that $\alpha_{1}=0$, where $\alpha_{1}$ is the $(n-r) \times r$ matrix of adjustment coefficients for the $I(1)$ variables that give rise to the permanent shocks driving the cointegrating relationships (see Pagan and Pesaran, 2008 for details). An important implication of this result is that it precludes the use of error correction terms in equations that define the permanent shocks.

Using (6), the permanent component of $Y_{t}$ can be written as

$$
\Delta \mathbf{y}_{t}^{p}=F B_{0}^{-1} \varepsilon_{t}
$$

Given (8), and following Dungey and Pagan (2009), equation (3) can be written in "gap deviation" form $\widetilde{\mathbf{y}}_{t}=\mathbf{y}_{t}-\mathbf{y}_{t}^{p}$ as the following:

$$
B^{*}(L) \Delta \widetilde{\mathbf{y}}_{t}=\alpha^{*} \beta^{\prime} \mathbf{y}_{t-1}-\Sigma_{j=1}^{p-1} B_{j}^{*} \Delta \mathbf{y}_{t-j}^{p}+B_{0}^{-1} \varepsilon_{t}
$$

where $\alpha^{*}=B_{0}^{-1} \alpha$. Since the gap variables are correlated with both the error correction terms and the changes in permanent components, exclusion of error correction terms will result in mis-specification (see Dungey and Pagan, 2009 for more details). Therefore, the conventional use of output gap will be replaced by the differenced output together with the corresponding error correction term for this variable; see also Karam and Pagan (2008).

\subsection{Estimating the Term Premium}

While the level of short-term interest rates is directed by the monetary authorities, aggregate spending decisions by households are heavily influenced by fluctuations in long-run interest rates, particularly via the mortgage markets. This link between the short and the long-run interest rates is crucial for successful monetary policy.

The expectations hypothesis plays a central role in the transmission mechanism across the term structure. The general form of the expectations hypothesis states that the $n$ period interest rate is an average of the current short rate and the future short-term rates expected 
to hold over the holding period of the long-term asset plus a constant term premium that varies with maturity. The empirical validity of constant term premium has been widely rejected. A possible alternative explanation includes a time-varying premia, $t p_{n, t}$, such as

$$
t p_{n, t}=r_{n, t}-\frac{1}{n} \sum_{i=0}^{n-1} E_{t} r_{t+i}
$$

where $r_{n, t}$ is the nominal yield to maturity of an $n$ period bond at time $t, r_{t}$ is the one-period rate, $n$ is the maturity period, $E_{t}$ is the expectation operator.

Several techniques have been proposed in the literature to derive a proxy for the expectations of future short rates; see Rudebusch et al. (2007) for a summary. A rather qualitative approach involves asking people directly about their expectations of the future interest rates by means of surveys. Despite its simplistic appeal, the uncertainty surrounding the possible responses, especially for long horizons, makes this method difficult to implement in practice. In fact, surveys of this kind do not exist for most countries, including the UK. Similar to the method proposed by Carriero et al (2006), we use the SVECM model described above to proxy for the model-consistent expectations of future short-run rates.

\subsection{Decomposition of the Term Premium}

As the term premium is made up of projections from the VAR model, it can, consequently, be analysed in terms of its component shocks. Consider that the interest rate can be expressed as a moving average process from the VAR

$$
r_{t}=\Sigma_{i=1}^{T} \widetilde{C}_{i} \varepsilon_{t-i}
$$

showing that the interest rate at each point in time is a weighted combination of shocks, with the weights provided by the impulse response functions. The decomposition of the term premium at each point in time reflects two sources of new information; information from changes in parameter estimates as well as the changes in the perception of old shocks. On the assumption that the model parameters are stable over time, which is supported by recursive estimation in our application (see Section 4.4), we attribute the new information to changes in perception brought about by the macro shocks. 


\section{Model Specification and Estimation}

The basis of the model conforms to a standard empirical modelling framework of an open economy IS curve, a Phillips curve, monetary policy reaction function and an exchange rate relationship. The model contains 5 variables: $\log$ foreign output, $y_{t}^{*}$, log domestic output, $y_{t}$, domestic inflation $\pi_{t}$, the short-run domestic interest rate, $r_{t}$ and the log real exchange rate, $q_{t}$, defined in units of domestic currency per unit of foreign currency. The foreign economy is taken to be the US, primarily because it represents world economic conditions and world financial conditions. ${ }^{2}$ Data definitions and relevant sources are given in Appendix. Figure 1 plots the variables for the sample period of 1980Q1 to 2007Q4.

Augmented Dickey Fuller tests show that foreign and domestic outputs, as well as the real exchange rate are unit root processes, see Table 1 . The inflation rate is stationary. Formal tests of the domestic interest rate cannot reject the existence of a unit root. However, as the interest rate is the policy instrument of the Central Bank in combating inflation, it is reasonable to follow the majority of the VAR literature and assume that they are stationary but highly persistent.

\subsection{Cointegrating Relationships}

The presence of unit roots in $y_{t}^{*}, y_{t}$ and $q_{t}$ raises the possibility of cointegration among the three variables. Theoretically, this supports an open economy IS curve, or traditional models of the equilibrium exchange rate such as the Mundell-Fleming model, where the equilibrium exchange rate is a function of the current account balance. This, in turn, depends on exports and imports, which are functions of the domestic and foreign outputs.

The estimated long-run relationship, normalized around the domestic GDP, is given by

$$
y_{t}=4.7148+0.8501 y_{t}^{*}+0.0355 q_{t}+e_{y t}
$$

where $e_{y t}$ is the residual from the equilibrium regression. ${ }^{3}$ The ADF test statistic rejects the null of a unit root in $e_{y t}$ with a MacKinnon test statistic of -2.289 and a p-value of 0.02 , confirming a cointegrating relationship between the three variables. ${ }^{4}$

The results obtained from the application of three different lag-order selection criteria are reported in Table 2. While the Akaike Information Criteria (AIC) point to a lag length

\footnotetext{
${ }^{2}$ Sensitivity analysis to using Euro Area data to represent world conditions produced similar results. An important future extension is to allow jointly for both Euro Area and US influences on the UK.

${ }^{3}$ Mills and Pentescot (2003) find no relationship between the real GDP of the UK, and the US and the real exchange rate for 1973-1999. However, this may be confounded by the change in exchange rate arrangements over their sample period.

${ }^{4}$ Johannsen test that includes constant and trend gives a pvalue of 0.09 .
} 
of 4, the Schwarz criterion (SC) and the Hannan-Quinn (HQ) criteria favour a lag order of 1 and 2 respectively. We use a lag length of 2 for the VAR in first differences in order to avoid overfitting the model while allowing for enough dynamics to capture the correlations in the data.

\subsection{Exclusion Restrictions}

The ordering of the contemporaneous relationships in the VAR reflects a small open economy. The most exogenous variable is foreign output, and the most endogenous is the real exchange rate. Between those, domestic output is followed by domestic inflation and the monetary reaction function, in an approach similar to that proposed in standard macroeconomics texts (see Bayoumi and Swiston, 2009).

The contemporaneous interaction between the reduced form $\left(u_{t}\right)$ and structural residuals $\left(\varepsilon_{t}\right)$, are given by the $B_{0}$ matrix, which is specified as follows:

$$
\left[\begin{array}{ccccc}
1 & 0 & 0 & 0 & 0 \\
\ominus & 1 & 0 & 0 & 0 \\
0 & \ominus & 1 & 0 & 0 \\
0 & \ominus & \ominus & 1 & 0 \\
\ominus & \ominus & \ominus & \ominus & 1
\end{array}\right]\left[\begin{array}{l}
u_{y_{t}^{*}} \\
u_{y_{t}} \\
u_{\pi_{t}} \\
u_{r_{t}} \\
u_{q_{t}}
\end{array}\right]=\left[\begin{array}{c}
\varepsilon_{y_{t}^{*}} \\
\varepsilon_{y_{t}} \\
\varepsilon_{\pi_{t}} \\
\varepsilon_{r_{t}} \\
\varepsilon_{q_{t}}
\end{array}\right]
$$

where $\varepsilon_{y_{t}^{*}}, \varepsilon_{y_{t}}, \varepsilon_{\pi_{t}}, \varepsilon_{r_{t}}$ and $\varepsilon_{q_{t}}$ are the structural residuals, the foreign output shock, domestic technology shock, domestic supply shock, domestic monetary policy shock and the real exchange rate shock respectively. The $\ominus s$ denote unrestricted elements.

The set of restrictions defined in equation (11) follow several considerations regarding the structure of the model. First, in line with the small open economy assumption, the foreign economy does not respond to the current values of domestic variables. The international linkages apply only through output with no direct linkages through inflation and interest rates, reflecting a New Keynesian IS curve. The monetary authority sets the interest rates with respect to current values of output and inflation. Finally, the real exchange rate equation reacts to all of the variables contemporaneously, reflecting the fact that exchange rates are forward-looking variables (Kim and Roubini, 2000). The lag matrices have a similar structure 
with additional dynamics

$$
B_{L}(L)=\left[\begin{array}{ccccc}
\ominus & 0 & 0 & 0 & 0 \\
\ominus & \ominus & \ominus & \ominus & \ominus \\
0 & \ominus & \ominus & 0 & \ominus \\
0 & \ominus & \ominus & \ominus & 0 \\
\ominus & \ominus & \ominus & \ominus & \ominus
\end{array}\right]
$$

The identification of the transitory and permanent shocks follows several considerations. The existence of 1 cointegrating vector among the three $I(1)$ variables indicates that there are 2 shocks with permanent effects and 1 shock with a transitory effect. The shocks to the inflation $\left(\pi_{t}\right)$ and the interest rate $\left(r_{t}\right)$ are also transitory since they are stationary processes. We associate the permanent shocks with domestic output $\left(y_{t}\right)$ and foreign output $\left(y_{t}^{*}\right)$, while we associate the transitory shock with the real exchange rate shock $\left(q_{t}\right)$. This is consistent with a somewhat different technology shock applied to each economy, as recently evidenced for the US and the Euro Area by Uhlig (2009).

The $\alpha$ matrix is specified by excluding error-correction terms for permanent shocks as explained in the previous section. The cointegrating vector $\beta$, which is normalized around domestic output, is augmented to include two pseudo-cointegrating vectors. The first two rows refer to the permanent shocks $y_{t}$ and $y_{t}^{*}$. While the speed of adjustment coefficients for the single cointegrating vector are placed in the first column, the second and third columns refer to the two $I(0)$ variables, $\pi_{t}$ and $r_{t}$. These variables are written in first difference forms as $x_{t}=\Delta x_{t}+\Psi x_{t-1}$ with the pseudo-ecm terms representing the coefficients of the lagged level terms in $\Psi$. The resulting $\alpha$ and $\beta$ matrices are defined as

$$
\alpha=\left(\begin{array}{ccc}
0 & 0 & 0 \\
0 & 0 & 0 \\
0 & \ominus & 0 \\
0 & \ominus & \ominus \\
\ominus & \ominus & \ominus
\end{array}\right) \quad \beta=\left(\begin{array}{ccc}
\ominus & 0 & 0 \\
1 & 0 & 0 \\
0 & 1 & 0 \\
0 & 0 & 1 \\
\ominus & 0 & 0
\end{array}\right) .
$$

Given the specification of $\alpha$ and $\beta$ matrices, the corresponding orthonormal components $\alpha_{\perp}$ and $\beta_{\perp}$ can be calculated, which leads to the following long-run impact matrix. The 
third, fourth and the fifth zero columns correspond to the transitory shocks.

$$
J=\left(\begin{array}{ccccc}
\ominus & 0 & 0 & 0 & 0 \\
\ominus & \ominus & 0 & 0 & 0 \\
0 & 0 & 0 & 0 & 0 \\
0 & 0 & 0 & 0 & 0 \\
\ominus & \ominus & 0 & 0 & 0
\end{array}\right)
$$

\section{Empirical Results}

The residual series obtained from the estimated model and the corresponding covariance matrix are depicted in Figure 2 and Table 3 respectively. It is evident that the size of the shocks has been smaller in magnitude after the inception of the inflation targeting regime in 1992. The correlations across the shocks are low, as shown in Table 3. (Given the zero restrictions in lag matrices $\mathrm{B}(\mathrm{L})$ in the specification, orthogonality is not strictly imposed by estimation.) In addition to the terms that appear in the above equations, dummy variables are included to control for distortions to inflation due to temporary factors such as indirect tax changes and price controls during 1991-92 period. All estimations are undertaken in Matlab.

\subsection{Impulse Response Analysis}

The rows in Figure 3 give the impulse responses for each variable to one standard error shock, where bootstrapped one standard error bands are shown with dashes. The small open economy assumption is represented by the lack of response in foreign output to any domestic shocks (rows 2 to 5 of column 1 in the figure).

A positive (permanent) foreign output shock (row 1) increases domestic output on impact, which subsequently stabilizes around its new level after 1 year. Domestic inflation peaks around the same time as a result of the higher domestic demand. Consequently, the monetary authority raises nominal interest rates, resulting in higher real interest rates, stabilizing inflation and output in the medium and long-term. The permanent nature of the shock causes relatively long-lived responses in endogenous variables. The highly persistent real depreciation of sterling in response to the foreign output shock reflects the larger increase in foreign output compared to domestic, but does not reflect UIP.

The impulse responses to a positive domestic output shock (row 2) are similar to those previously discussed, but the higher real interest rate induces a permanent appreciation of the real exchange rate. The higher interest rates and appreciated domestic currency help to 
stabilize domestic output around 1 year after the initial shock.

The impulse responses to a positive supply shock (row 3) show a tightening in monetary policy via higher nominal interest rates in response to higher inflation, which results in lower output. The real exchange rate appreciates on impact before it depreciates. The responses to a positive monetary policy surprise (row 4) is also as expected, where higher interest rates increase marginal cost for the producers and output declines. We observe an initial price puzzle, where inflation picks up slightly; however, the effect is not significant. Inflation then declines and gradually stabilizes in the medium term. Given that the US interest rates are unchanged, higher domestic interest rates cause a real appreciation of the domestic currency, which reduces output through its negative impact on exports.

\subsection{Historical Decompositions}

Historical decompositions reflect a rearrangement of impulse response coefficients into a history of contributing shocks to observed outcomes. The first column in Figure 4 shows the 5 contributing shocks to the evolution of domestic GDP over the sample period. While own shocks are dominant, foreign output shocks are seen to have played a distinct role. Although the contribution of domestic output shocks was largely positive before the period of inflation targeting, there was a substantial drop associated with the early 1990s recession and the start of inflation targeting at the end of 1992. Consistent with the existing literature, monetary policy shocks have not played a significant role in explaining the total variation in real GDP (see also Mountford, 2005).

The second column in Figure 4 shows the historical decomposition of inflation. While, again, own shocks have been the main determinant of the total variation in UK inflation, domestic output shocks have had a slight impact.

Finally, the last column in Figure 4 shows the historical decomposition of the domestic interest rates. Inflation shocks have been the major contributor. Prior to the switch to inflation targeting, inflation shocks were primarily positive and tended to increase the interest rate. Post 1992, there is more evidence of inflation shocks contributing to lower interest rates. Domestic output shocks also had a positive impact on interest rates during 1980-1992, with a noticeable dip at the time of the early 1990s recession, but with relatively little influence since.

\subsection{Assessing Shocks in 2007-2008}

In this section, we use the model to shed some light on the relative magnitude of the adverse shocks to the UK economy during the crisis period of 2007-2008. To establish the credentials 
of the model, we first conduct an out-of-sample forecasting exercise based on the model estimated for the period 1980Q1-2006Q4, prior to the crisis, and project it onto the following 4 quarters between 2007Q1-2007Q4.

The first column of charts in Figure 5 shows the forecasts of GDP, inflation and interest rates for the period 2007Q1-2007Q4. The model is able to track the actual dynamics of GDP reasonably well during 2007. The estimated average annual growth rate is projected as 2.5 percent during which the corresponding OECD estimate is 5.2 percent. The forecasts for inflation and interest rates also track the dynamics relatively well.

We then forecast the next four quarters between 2008Q1-2008Q4 from the model estimates reported in previous sections (to 2007Q4), a period in which the effect of the financial crisis is more pronounced. These forecasts are compared with actual data to judge the divergence between them. The resulting charts are given in the second column of Figure 5 . The differences are striking and give an idea of the extent of the adverse shock that hit the UK economy during the financial crisis. The model is not able to reflect the negative growth rates observed during 2008 and projects a modest growth rate of around 0.5 percent throughout that year. The model projected a slight decline in inflation during 2008, but not the extent of volatility induced by the crisis shocks.

Finally, the last figure in the second column shows the results for the short-term interest rates, where we also observe a huge discrepancy between the actual and forecast values throughout 2008. The sharp decline in policy rates in response to the contraction in demand is evident in the figures. Overall, the results highlight the severity of the adverse shock experienced by the UK economy, where the outcomes cannot be forecast using aggregate historical relationships alone.

\subsection{Parameter Stability Test}

In this section, we test the robustness of the estimated model to the sample. Figure 6 shows the plots of recursive residuals from each model equation. These are calculated by recursively estimating the model with ever-larger subsets of data, forecasting the next value of the dependent variable in each step and calculating the corresponding residuals. Residuals that fall outside the plus and minus two standard error bands (the dotted lines) are indicative

of a potential parameter instability in the equation. Overall, the model equations are quite stable over time. 


\section{The Term Premium}

The term premium is constructed using recursive forecasts from the model. At each point in time the model is estimated and short-term interest rates projected out-of-sample up to 10 years ahead. Model estimation begins for the sample 1980Q1-1995Q4 after the inception of the inflation targeting regime in 1992 and uses the estimated coefficients to forecast shortrun rates for the 10-year horizon. The forecasts of short-run rates over the holding period of the long-term bond are averaged, thereby obtaining series of expected long-run rates for various maturities over the period 1996Q1-2007Q4. Given that these estimates depend only on observed values of the macroeconomic variables, long-term and short-term rates, they are interpreted as reflecting the market's expectation of the future short-term rate. The difference between the actual and the predicted values for 10 year government yields then gives the associated term premium.

Figure 7 shows the 10-year term premium calculated as the difference between the actual and predicted interest rates for the 10-year bond for the period 1996Q1-2007Q4. Consistent with the results in Bianchi et al. (2009), the term premium is estimated to be negative for a considerable portion of the sample. However, the current results do not display the persistent downward trend of Bianchi et al.'s less preferred fixed coefficients VAR model. The events pinpointed on Figure 7 suggest that while the Bank of England's independence in 1997 played an important role in reducing the risk premium demanded by investors, the Russian crisis and general elections of 2001, 2004 and 2005 seem to have played a reverse role.

From the perspective of the model, the overall outcome may be explained as follows. The negative term premia estimated for the sample period show that the model systematically over-predicts the 10- year rates, computed by averaging the forecasts of short-term interest rates over the forecast horizon. Given the uncertainty surrounding the estimates over the 10year horizon, this can partly be explained by the forecast inaccuracy inherent in the forecasts. At the same time, this is an indication that the model is excluding an important determinant of interest rates that was relevant during the forecast period. In this respect, it is possible that the model is unable to capture the positive confidence boost induced by the decision to grant operational independence to the Bank of England in 1997. This, in our view, is an important contributor to the negative term premia observed during this period. Therefore, the systematic forecast errors can be explained by the behaviour of agents making large and persistent forecast errors following a policy rule change while they learn about the new policy framework (Ferderer and Shadbegian, 1993; Ellingsen and Söderström, 2001). 


\subsection{Decomposition of the Term Premium}

Figure 8 shows the historical decomposition of the term premium during 1995Q4-2007Q4. It is evident that the majority of the dynamics are driven by negative shocks in inflation and interest rates. The relationship between the interest rate and term premium reflects the positive association with the level of short-term interest rates in Kessel (1965).

Although interest rates contribute substantially to the term premium in the estimation period, in general, the largest contribution has been through negative inflation shocks. This is most evident in the 2000-2002 period, coincident with the bursting of the dot-com bubble and associated economic slowdown. Expectations about future inflation paths are clearly influential on revisions to the term premium in the model, as would be expected.

\subsection{The Term Premium in 2008}

Using the macroeconomic forecasting framework previously described in Section 4.3, we can also decompose the corresponding forecast of the term premium. The forecast for 2008 is given as the final four observations for the solid black line in Figure 9. It is evident that the term premium drops considerably in 2008. Interestingly, the extent of the drop in the term premium in this crisis period is quite similar to the strongly negative term premium experienced in the crisis associated first with the Russian default of August 1998 and the subsequent near collapse of the US-based hedge fund, Long-Term Capital Management.

Figure 9 also shows the decomposition of the shocks of the term premium, including for the forecast. In this case, static forecasting was used, so that the lagged interest rates in particular were replaced with their actual values as the one-period forecast advanced. Without this, it is clear from the interest rate forecasts presented in Figure 5 that the extent of the interest rate shocks cannot be captured from the model. Once this is taken into account, Figure 9 reveals the dominant role of the sharp drops in interest rates during the 2007-2008 crisis in the drops in the term premium. The sharp negative drop in term premium during the crisis is likely to be associated with an overwhelming investor rush to short-dated quality securities (cash), reflecting great uncertainty about longer-dated securities. This was also a feature of the 1998 crisis (see; for example, Dungey et al., 2008 and Upper et al., 2002). Interestingly, despite this, output shocks contributed positively to the term premium, indicating that in fact, given the conditions in the economy, output held up more resiliently than would have been expected. Inflation shocks did not make a particular contribution to the term premium, which, arguably, reflects the expectation that the credibility of the inflation targeting policy of the central bank was not threatened by the crisis events. 


\section{Conclusion}

This paper contributes three new aspects to the literature. The primary result is estimation of the term premium from a fully specified, small open economy VAR model. We show that this model can be used to decompose the changes in the term premium to contributing shocks in macroeconomic conditions affecting the underlying expectations of economic agents. The second contribution is the specification and estimation of a VAR model of the UK economy, combining identification by exclusion restrictions and cointegration to incorporate data of mixed $\mathrm{I}(0)$ and $\mathrm{I}(1)$ nature as well as permanent and temporary shocks in an empirically consistent manner. Finally, the estimated framework for the UK to 2007 is used to project into the recent financial crisis period, quantifying the extent of the shocks hitting the UK economy and the impact of these shocks on the term premium.

The dominant role of inflation and interest rate shocks in explaining the UK term premium is supported by the results. Projections from the model are used to estimate a timevarying term premium for the UK 10 year bond yields, and reveal a persistently negative term premium over the majority of the period. The evolution of the term premium is shown to be mainly influenced by shocks originating from interest rate changes and, most importantly, from inflation. Although the model performs well in projecting into 2007, the extent of the shocks hitting the UK economy in 2008 is demonstrated by the extraordinary deviation of the model projection from the actual data in 2008. The forecasting framework is used to show that the current crisis has similarities with the 1998 Russian crisis in that it resulted in a substantial widening of the negative term premium. However, unlike in the Russian crisis, inflation shocks in 2008 did not contribute to the wider term premium, reflecting the sustained credibility of the central bank policy regime. 


\section{References}

Akram, Q. F., And R. Nymoen (2009): "Model selection for monetary policy analysis: how important is empirical validity?," Oxford Bulletin of Economics and Statistics, 71(1), $35-68$.

Bayoumi, T., and A. Swiston (2009): "Foreign entanglements: estimating the source and size of spillovers across industrial countries," IMF Staff Papers, 56(2), 353-383.

Beenstock, M., and J. A. Longbottom (1981): "The term structure of interest rates in a small open economy," Journal of Money, Credit and Banking, 13(1), 44-59.

Bianchi, F., H. Mumtaz, and P. Surico (2009): "The great moderation of the term structure of UK interest rates," Journal of Monetary Economics, 56(6), 856-871.

Blanchard, O., and J. Simon (2001): "The long and large decline in US output volatility," Brookings Papers on Economic Activity, 2001(1), 135-164.

Carriero, A., C. A. Favero, and I. Kaminska (2006): "Financial factors, macroeconomic information and the Expectations Theory of the term structure of interest rates," Journal of Econometrics, 131(1-2), 339-358.

Cecchetti, S. G., A. Flores-Lagunes, and S. Krause (2006): "Assessing the Sources of Changes in the Volatility of Real Growth," NBER Working Papers 11946, National Bureau of Economic Research, Inc.

Dennis, R., K. Leitemo, and U. Söderström (2007): "Monetary policy in a small open economy with a preference for robustness," CEPR Discussion Papers 6067.

Dungey, M., And R. Fry (2009): "The identification of fiscal and monetary policy in a structural VAR," Economic Modelling, 26(6), 1147-1160.

Dungey, M., C. Goodhart, and D. Tambakis (2008): "The US treasury market in August 1998: untangling the effects of Hong Kong and Russia with high-frequency data," International Journal of Finance \& Economics, 13(1), 40-52.

Dungey, M., And A. R. Pagan (2009): "Extending a SVAR model of the Australian economy," Economic Record, 85, 1-20.

Ellingsen, T., and U. Soderstrom (2001): "Monetary policy and market interest rates," American Economic Review, 91(5), 1594-1607. 
FERderer, J. P., And R. Shadbegian (1993): "A comparison of alternative term premium estimates," The Quarterly Review of Economics and Finance, 33(2), 179 - 195.

Greenspan (2005): "Testimony to the congress, 16 February," .

Joyce, M., I. Kaminska, and P. Lildholdt (2008): "Understanding the real rate conundrum: an application of no-arbitrage finance models to the UK real yield curve," Bank of England working papers 358, Bank of England.

Joyce, M. A., P. Lildholdt, and S. Sorensen (2010): "Extracting inflation expectations and inflation risk premia from the term structure: A joint model of the UK nominal and real yield curves," Journal of Banking \& Finance, 34(2), 281-294.

Karam, P. D., And A. PAGAn (2008): "A small structural monetary policy model for small open economies with debt accumulation," IMF Working Papers 08/64, International Monetary Fund.

Kessel, R. A. (1965): The cyclical behavior of the term structure of interest rates, no. kess65-1 in NBER Books. National Bureau of Economic Research, Inc.

Kim, S., And N. Roubini (2000): "Exchange rate anomalies in the industrial countries: A solution with a structural VAR approach," Journal of Monetary Economics, 45(3), $561-586$.

Leitemo, K. (2006): "Targeting inflation by forecast feedback rules in small open economies," Journal of Economic Dynamics and Control, 30(3), 393-413.

Lutkepohl, H., and M. Kratzig (2004): Applied time series econometrics. Cambridge Univ Press.

Mills, T. C., And E. J. Pentecost (2003): "Is there a relationship between real exchange rate movements and the output cycle?," Economic Modelling, 20(3), 593-603.

Mountford, A. (2005): "Leaning into the wind: A structural VAR investigation of UK monetary policy," Oxford Bulletin of Economics and Statistics, 67(5), 597-621.

Pagan, A., And M. H. Pesaran (2008): "Econometric analysis of structural systems with permanent and transitory shocks," Journal of Economic Dynamics and Control, 32(10), $3376-3395$. 
Ravn, M. (1992): "Business cycles in the U.K.: A small open economy in the interdependent world," Economics Working Papers 1992-12, School of Economics and Management, University of Aarhus.

Rudebusch, G., B. Sack, and E. Swanson (2007): "Macroeconomic implications of changes in the term premium," Review-Federal Reserve Bank Of Saing Louis, 89(4), 241.

Uhlig, H. (2009): "Monetary policy in Europe vs the US: what explains the difference?," NBER Working Papers 14996, National Bureau of Economic Research, Inc.

Upper, C., T. Werner, and D. Bundesbank (2002): "How resilient are financial markets to stress? Bund futures and bonds during the 1998 turbulence," Bank for International Settlements Papers, 12, 110-123. 


\section{Appendix:Variable Descriptions}

\begin{tabular}{clc}
\hline \hline Data definitions & \multicolumn{1}{c}{ Definition } & Source \\
\hline$y^{*}$ & $\log$ Real GDP VOL constant 2000 prices, National Currency & IFS(99B.RZF) \\
$y$ & $\log$ Real GDP, constant 2006 prices, National Currency & OECD Database \\
$\pi$ & UK CPI, \% Change per annum. & IFS (64..XZF ) \\
$r$ & UK Treasury Bill Rate, \% per annum & IFS(60C..ZF) \\
$q$ & 100 times the quarterly average of the £UK/\$US & \\
& nominal exchange rate and the ratio of UK:US CPI & IFS, Datastream \\
$r 10$ & 10-Year Government bond yield, \% & Bank of England website \\
\hline
\end{tabular}




\section{Figures and Tables}

Table 1: Augmented Dickey Fuller Unit Root Test

\begin{tabular}{lccccc}
\hline \hline Levels & $y$ & $y^{*}$ & $\pi$ & $r$ & $q$ \\
\hline TS & -2.59 & -3.02 & -4.01 & -2.40 & -2.94 \\
CV (5 \%) & -3.45 & -3.45 & -2.89 & -2.89 & -3.45 \\
Unit Root & + & + & - & + & + \\
\hline First Diff. & $d(y)$ & $d\left(y^{*}\right)$ & $d(\pi)$ & $d(r)$ & $d(q)$ \\
\hline TS & -4.57 & -4.16 & -6.32 & -8.80 & -8.23 \\
CV (5 \%) & -2.88 & -2.88 & -2.88 & -2.88 & -2.88 \\
Unit Root & - & - & - & - & - \\
\hline \hline
\end{tabular}

Note: The lag lengths are selected based on AIC. The maximum lag length is set to 4. The ADF statistics for all level variables are based on regressions including constant and linear trend with the exception of the inflation and interest rate, which include constant only.

Table 2: Lag Selection Criteria

\begin{tabular}{lccc}
\hline \hline Lag length & AIC & SC & HQ \\
\hline 0 & 0.38 & 0.51 & 0.43 \\
1 & -14.56 & $-13.81^{*}$ & -14.26 \\
2 & -14.88 & -13.51 & $-14.32^{*}$ \\
3 & -14.76 & -12.78 & -13.96 \\
4 & $-15.11^{*}$ & -12.50 & -14.05 \\
\hline
\end{tabular}

Table 3: Residual Correlation Matrix

\begin{tabular}{rrrrrr}
\hline \hline & $u_{y^{*}}$ & $u_{y}$ & $u_{\pi}$ & $u_{r}$ & $u_{q}$ \\
\hline$u_{y^{*}}$ & 1.00 & & & & \\
$u_{y}$ & 0.00 & 1.00 & & & \\
$u_{\pi}$ & -0.08 & 0.00 & 1.00 & & \\
$u_{r}$ & 0.09 & -0.02 & 0.05 & 1.00 & \\
$u_{q}$ & 0.00 & 0.00 & -0.08 & 0.00 & 1.00 \\
\hline
\end{tabular}



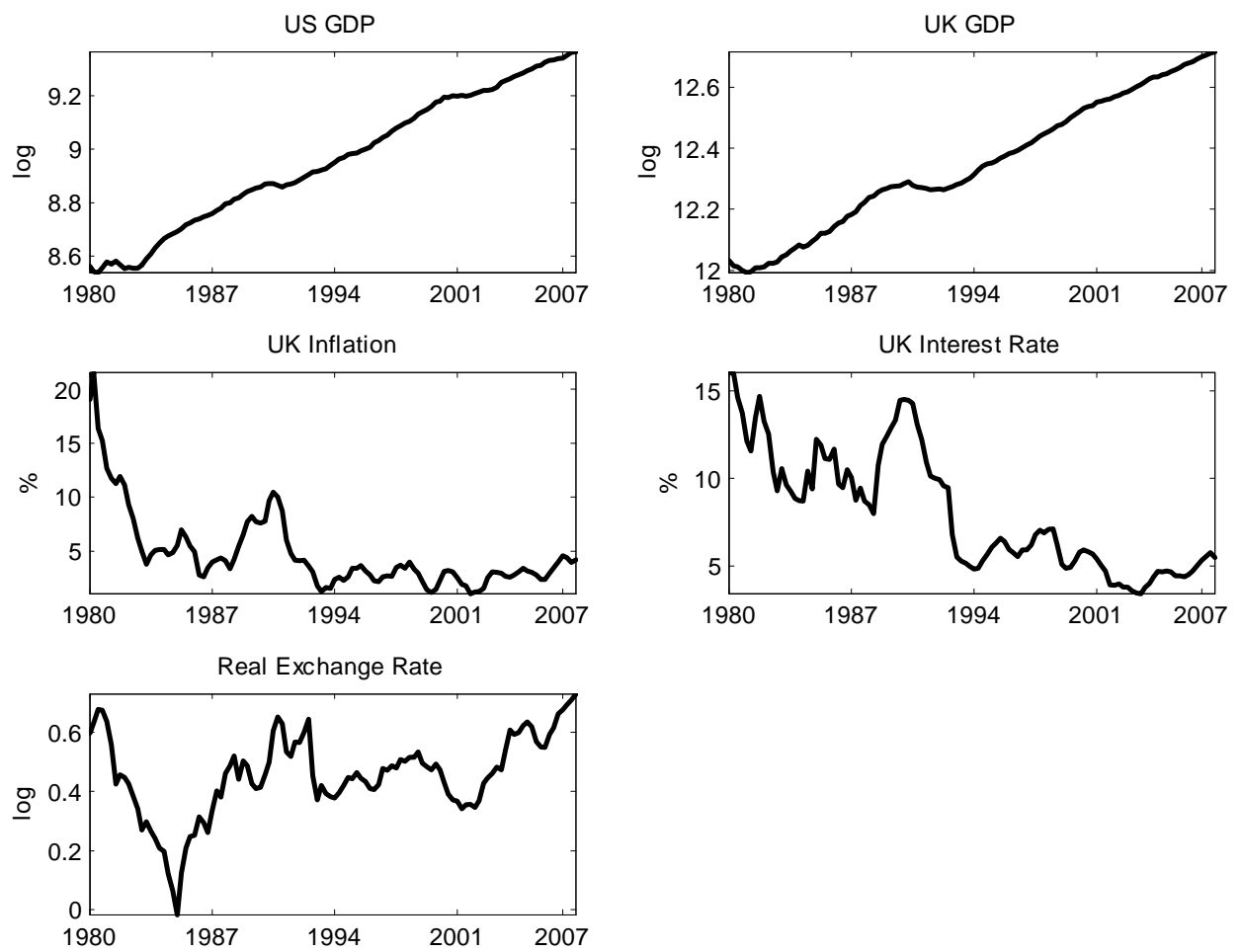

Figure 1: Variable Plots
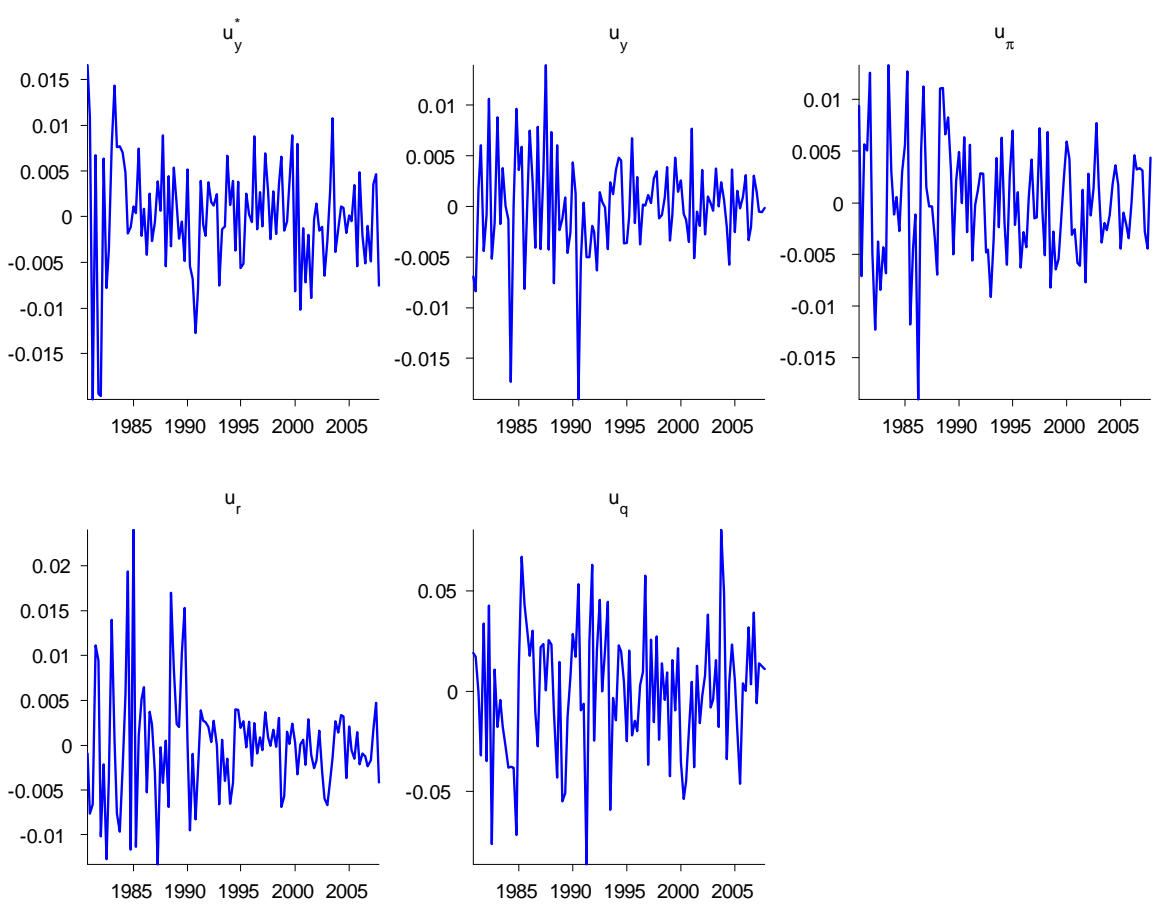

Figure 2: Residual Plots 

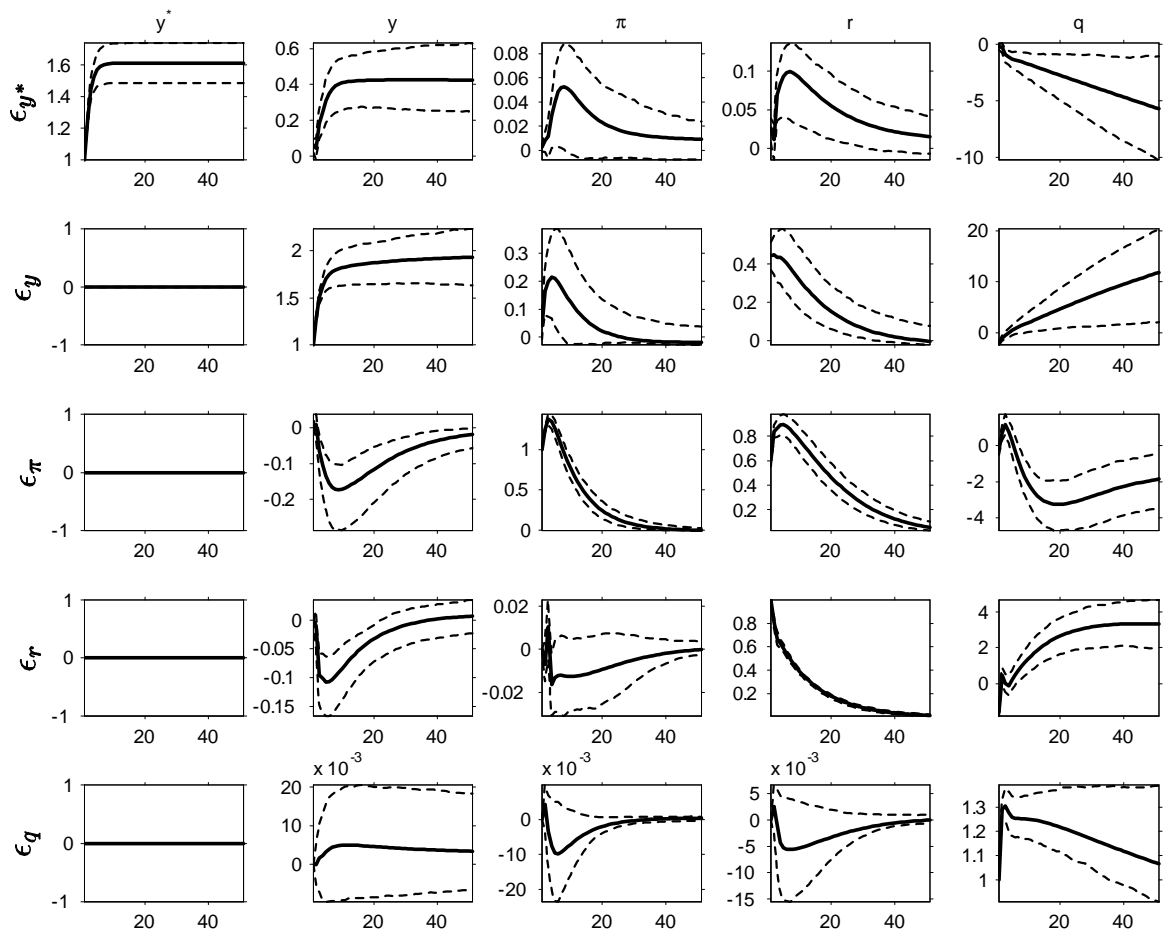

Figure 3: Impulse Response Functions 

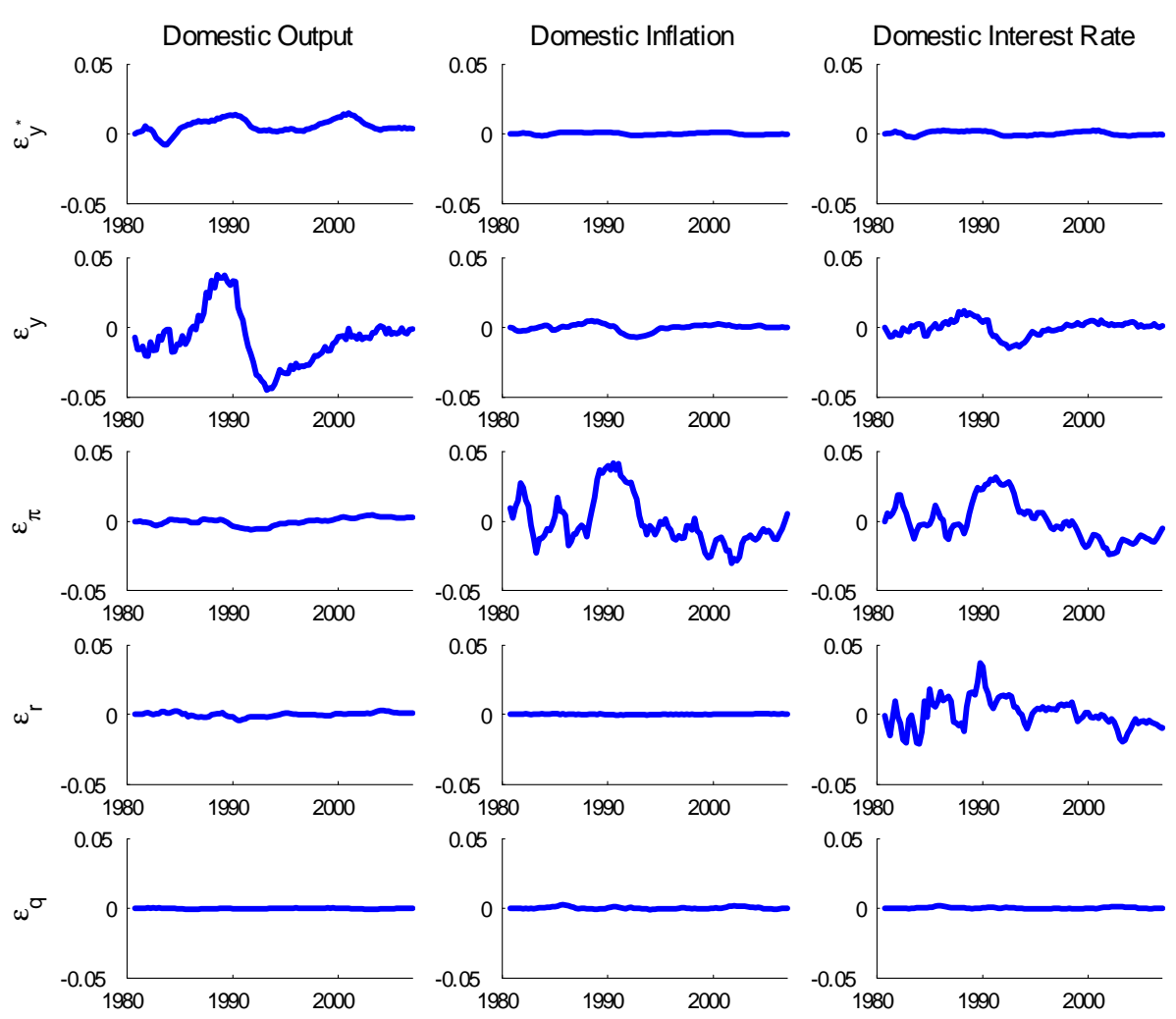

Figure 4: Historical Decompositions 

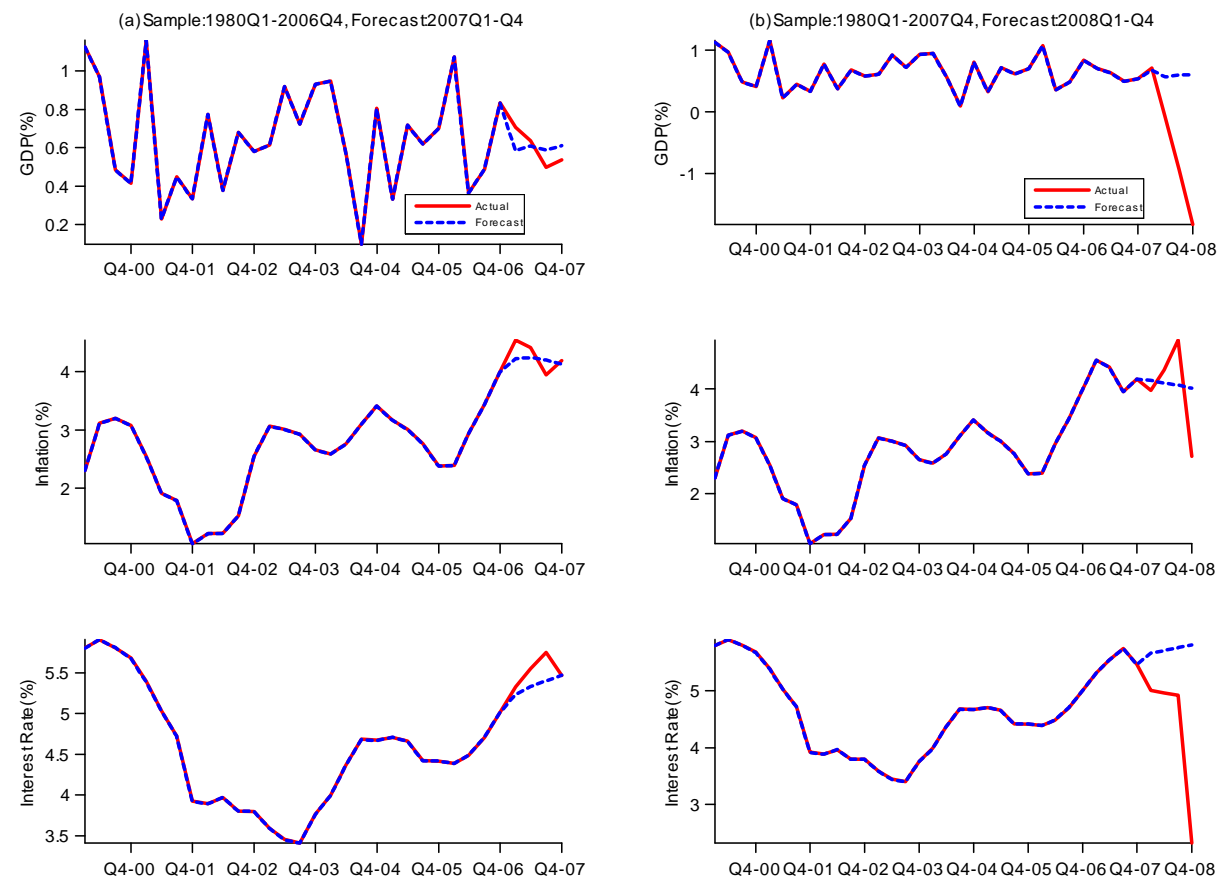

Figure 5: Macro Forecasts
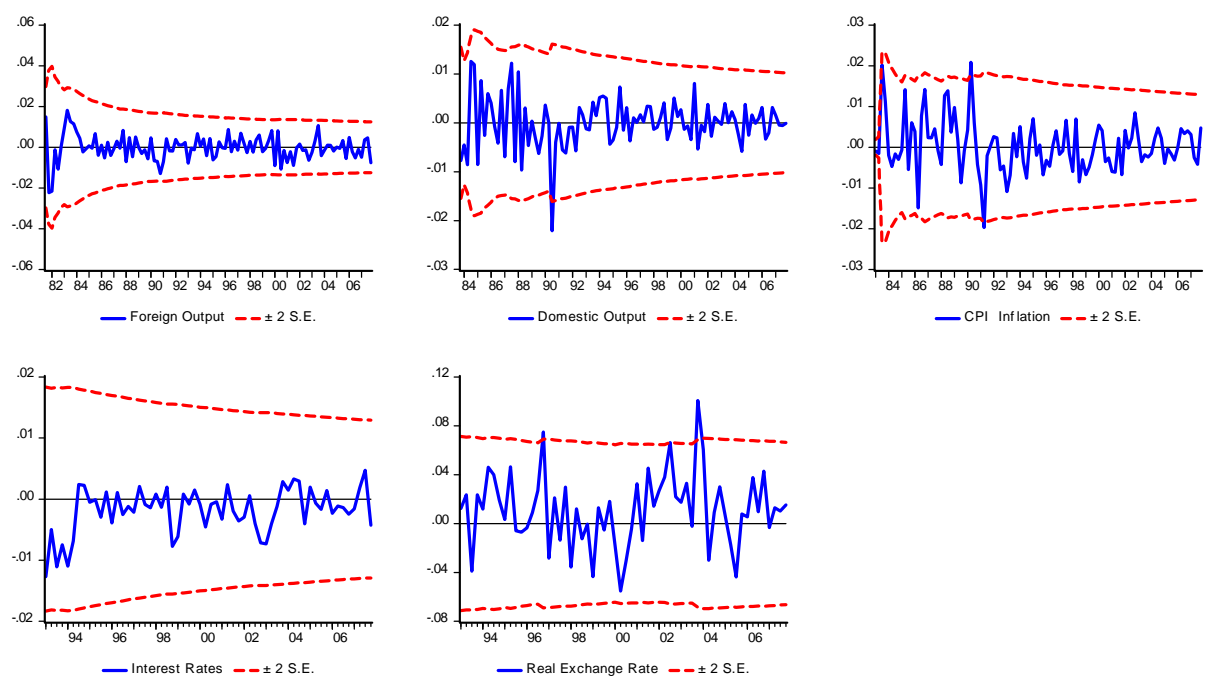

Figure 6: Recursive Residuals 

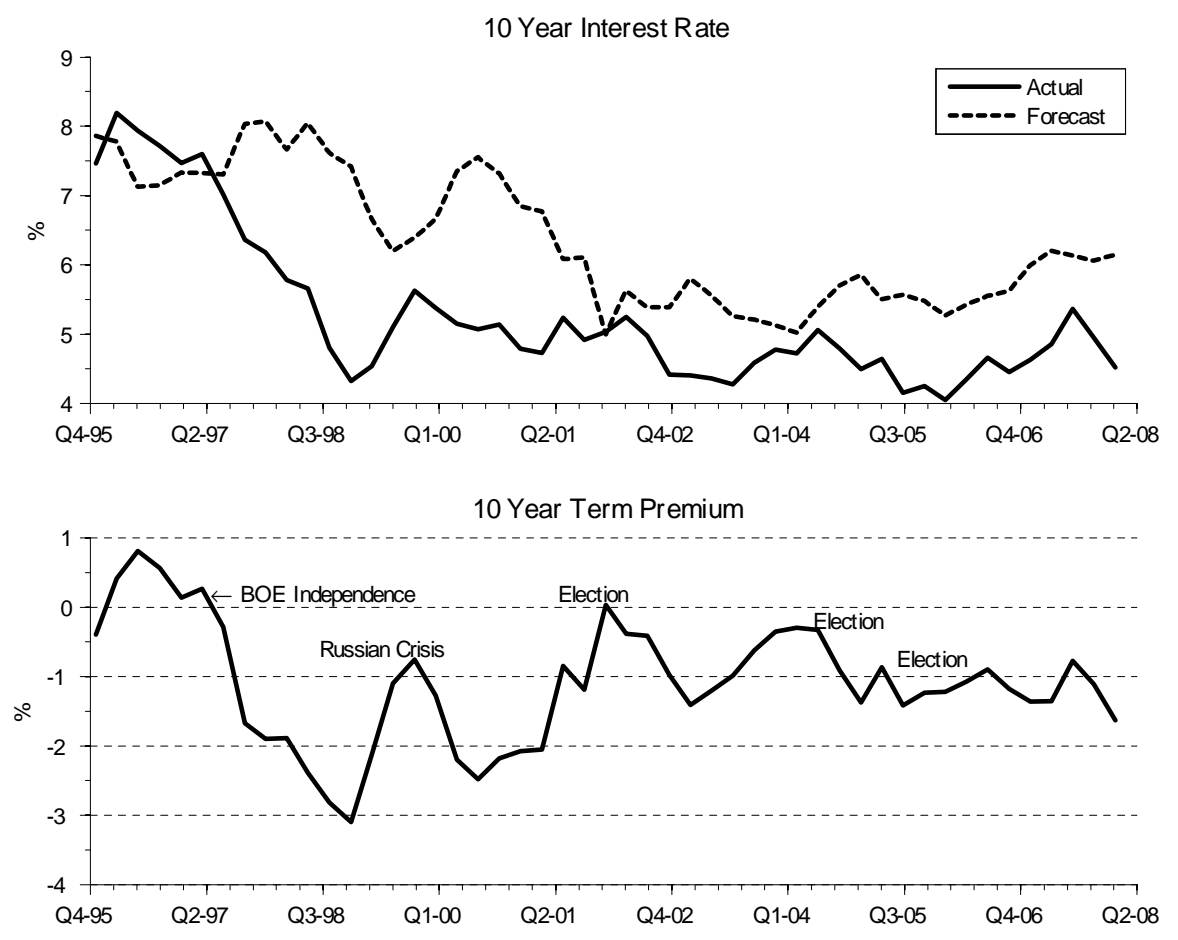

Figure 7: 10-Year Term Premium
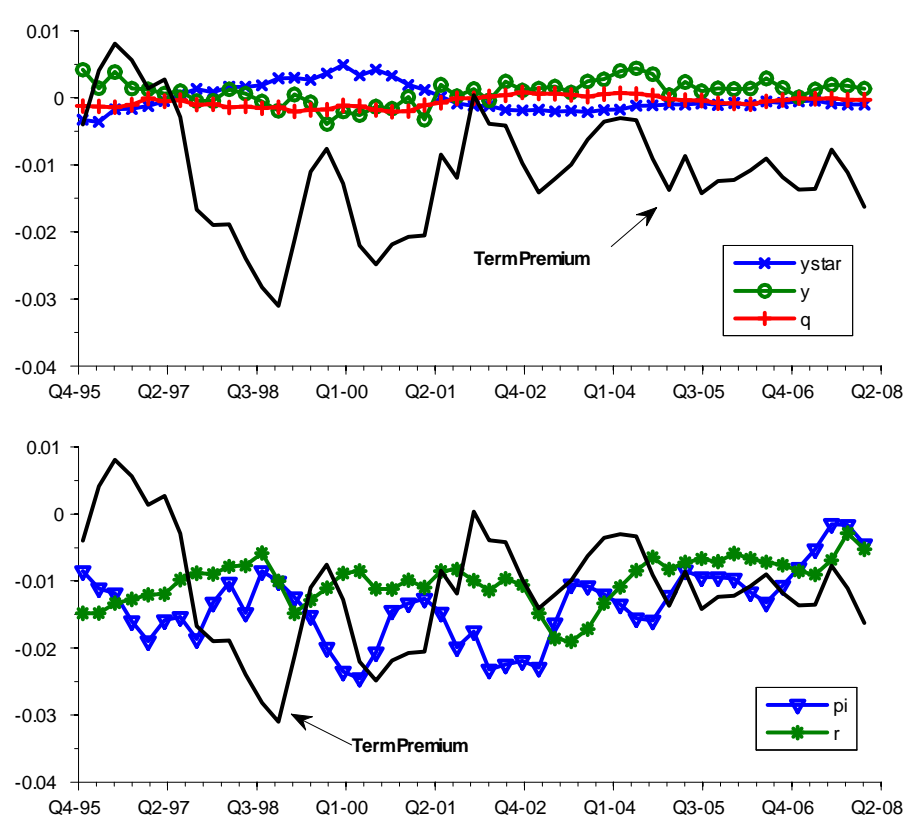

Figure 8: Recursive Decomposition of the Term Premium 


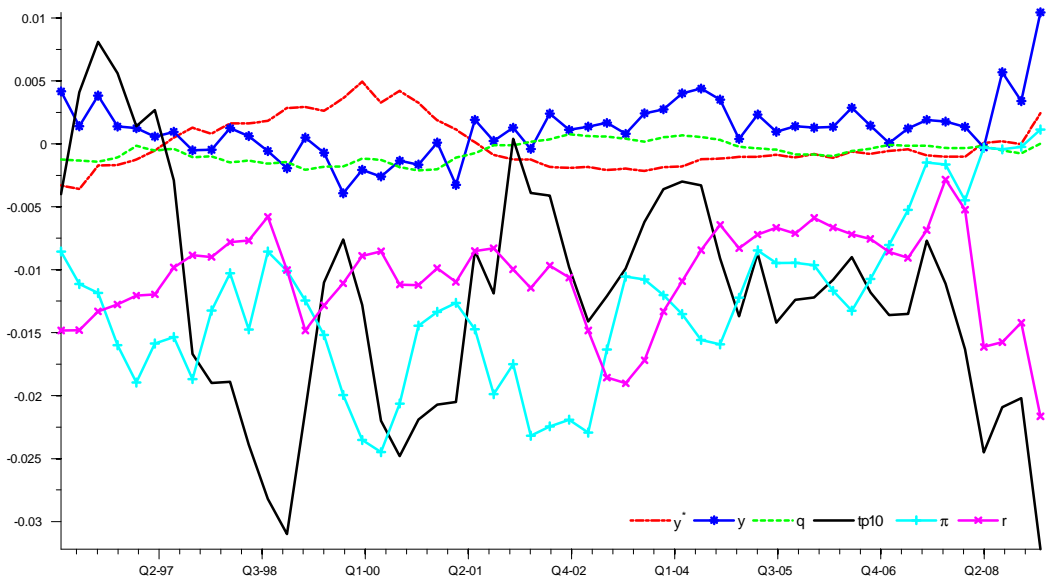

Figure 9: Term Premium Forecast for 2008 and its Historical Decomposition 


\section{School of Economics and Finance Discussion Papers}

2011-05 A SVECM Model of the UK Economy and The Term Premium, Mardi Dungey and M. Tugrul Vehbi

2011-04 Do Contact Matter in the Process of Getting a Job in Cameroon? Firmin Doko Tchatoka and Urbain Thierry Yogo

2011-03 Subset Hypotheses Testing and Instrument Exclusion in the Linear IV Regression, Firmin Doko Tchatoka

2011-02 First home Buyers’ Support Schemes in Australia - Results Spreadsheet, Mardi Dungey, Graeme Wells and Sam Thompson

2011-01 First home Buyers’ Support Schemes in Australia, Mardi Dungey, Graeme Wells and Sam Thompson

2010-12 Financial Crises in Asia: Concordance by Asset Market or Country?, Mardi Dungey, Jan P.A.M. Jacobs and Lestano

2010-11 Innovation Contracts with Leakage Through Licensing, Shane B. Evans

2010-10 Franchise Contracts with Ex Post Limited Liability, Shane B. Evans

2010-09 Menus of Linear Contracts in Procurement with Type-Dependent Reservation Utility, Shane B. Evans

2010-08 Decomposing the Price Effects on the Cost of Living for Australian Households, Paul Blacklow

2010-07 Modelling the Time Between Trades in the After-Hours Electronic Equity Futures Market, Mardi Dungey, Nagaratnam Jeyasreedharan and Tuo Li

2010-06

Cojumping: Evidence from the US Treasury Bond and Futures Markets, Mardi Dungey and Lyudmyla Hvozdyk

2010-05 Assessing the Impact of Worker Compensation Premiums on Employment in Tasmania, Paul Blacklow

2010-04 Non-Linear Pricing with Homogeneous Customers and Limited Unbundling, Hugh Sibly

2010-03 Detecting Contagion with Correlation: Volatility and Timing Matter, Mardi Dungey and Abdullah Yalama

2010-02 From Trade-to-Trade in US Treasuries, Mardi Dungey, Olan Henry and Michael McKenzie

2010-01 Economic Assessment of the Gunns Pulp Mill 2004-2008, Graeme Wells

Copies of the above mentioned papers and a list of previous years' papers are available from our home site at http://www.utas.edu.au/ecofin 